\begin{abstract}
ARTICULO
Revista Derecho - Año 3 edicion $500-00$

Web: http://revistas.unap.edu.pe/rd E-mail.com: revistaderecho@unap.edu.pe ISSN 2313-6944

\section{INFLUENCIA DE FACTORES BIOPSICOSOCIALES EN EL ANALISIS DEL CASO YYY EN LA COMISION DE DELITO EN ESTADO DE EBRIEDAD DESDE LA CRIMINOLOGIA CLINICA}

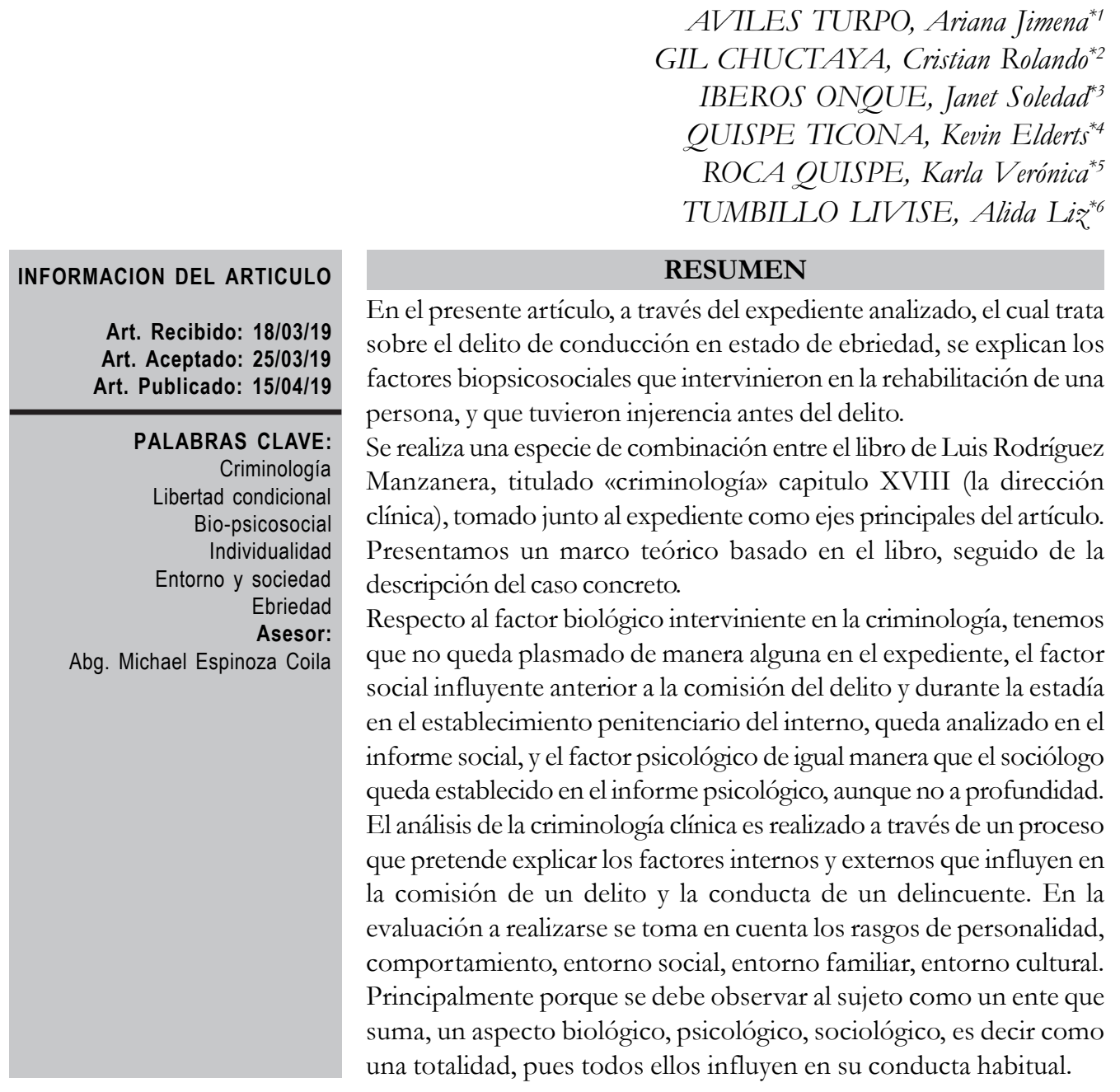

* Universidad Nacional del Altiplano, Facultad de Ciencias Jurídicas y Políticas, Escuela Profesional de Derecho 'avilesj2190@gmail.com-2Tom_kent100@hotmail.com-3JSoledadIberos98@gmail.com-5karlaveronica_osa@hotmail.com ${ }^{6}$ Alidalt138@gmail.com 
INFLUENCE OF BIOPSYCHOSOCIAL FACTORS IN THE ANALYSIS OF THE YYY CASE IN THE COMMISSION OF CRIME IN THE STATE OF DRINK SINCE OF CLINICAL

\section{CRIMINOLOGY}

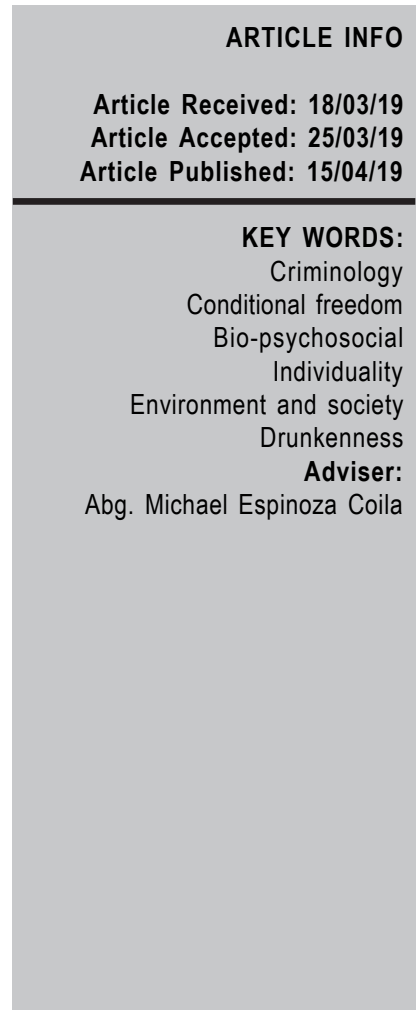

\section{ABSTRACT}

In this article, through the file analyzed, which deals with the offense of driving while intoxicated, the biopsychosocial factors that intervene in the rehabilitation of a person, and that had interference before the crime, are explained.

A kind of combination is made between the book by Luis Rodríguez Manzanera, entitled «criminology» chapter XVIII (the clinical direction), taken together with the file as main axes of the article. We present a theoretical framework based on the book, followed by the description of the specific case.

Regarding the biological factor intervening in criminology, we have not been reflected in any way in the file, the influential social factor prior to the commission of the crime and during the stay in the penitentiary establishment of the inmate, is analyzed in the social report, and the psychological factor in the same way that the sociologist is established in the psychological report, although not in depth.

The analysis of clinical criminology is conducted through a process that aims to explain the internal and external factors that influence the commission of a crime and the behavior of an offender. In the evaluation to be carried out, personality traits, behavior, social environment, family environment, cultural environment are taken into account. Mainly because the subject must be observed as a being that adds up, a biological, psychological, sociological aspect, that is, as a totality, since all of them influence their habitual behavior.

100 Revista Derecho - 5 (2019) 


\section{MARCO TEORICO}

Benigno Di Tullio mencionaque la criminología clínica debe entenderse como «la ciencia de las conductas antisociales y criminales, basada en la observación y el análisis profundo de casos individuales, sean éstos normales, anormales o patológicos.»(Tullio, 1955)

Es una corriente criminológica, que intentó, con bastante éxito, reunir las tres corrientes (biológica, psicológica y sociológica), y dar una explicación integral del caso concreto, al considerar al hombre como una unidad biopsicosocial.

De acuerdo con Rodríguez Manzanera, la criminología clínica tiene por objeto, formular una opinión sobre el delincuente, conteniendo un diagnóstico, un pronóstico, y próximamente un tratamiento.

La Criminología Clínica es ante todo Criminología aplicada. Existen tres niveles de interpretación: el conductual (crimen), el individual (criminal), y el general (criminalidad); la Criminología clínica opera en el segundo nivel, analiza al sujeto antisocial en concreto, en su realidad personal e irrepetible.

La corriente de la criminología clínica parte de la base de considerar al hombre como una unidad biopsicosocial. No podemos ver al hombre únicamente desde un punto de vista ni nada más de una de sus facetas, tenemos que verlo como una totalidad, tenemos que verlo como ente biopsicosocial, porque está formado por de un potencial biológico, tiene una herencia, pero no podemos resumirlo solo eso, además el hombre tiene una psique, que es su forma de ser, más aun es un ser que vive en sociedad, por lo tanto su pensamiento y su forma de ser es influenciada por la sociedad, llevándonos a analizar las causas biológicas, psicológica y sociológicas.

En la criminología Clínica moderna se considera, que, así como dos resfriados son distintos según el paciente, un homicidio cometido por una persona es distinto al cometido por otra, nunca encontraremos dos crímenes idénticos, siempre habrá notables factores de variabilidad de un sujeto a otro. (Rodriguez Manzanera, 1981)

\section{DESCRIPCIÓN DEL CASO EN CONCRETO}

En agosto del año dosmil trece YYY(como llamaremos al interno), es detenido por conducir en estado de ebriedad, subsumiendo dicha conducta en el primer párrafo del artículo 274 del Código Penal.

Mediante resolución $\mathrm{N}^{\circ} 10$ del once de agosto del dos mil quince se expone lo siguiente:

Revista Derecho - 5 (2019) 101 
En un primer momento el fiscal solicita un año de pena privativa de libertad efectiva e inhabilitación por el mismo periodo de tiempo, además del pago de reparación civil de mil ciento cuarenta nuevos soles,

El imputado acepta los hechos y se somete a la conclusión anticipada del juicio oral, por lo que el juzgado declara la conclusión anticipada del juicio oral. Reabierta la audiencia, el fiscal da a conocer los siguientes acuerdos:

1) Que al acusado se le imponga diez meses y veinte días de pena privativa de libertad suspendida, indicando como reglas de conducta:

a) La prohibición de frecuentar lugares donde se expenda bebidas alcohólicas.

b) La prohibición de ausentarse del lugar donde reside, sin autorización del juez.

c) Comparecer mensualmente al juzgado, personal y obligatoriamente para informar y justificar sus actividades.

d) Cumplir con el pago de reparación civil.

2) Se fije por concepto de reparación civil la suma de novecientos noventa y cinco nuevos soles. Así mismo se le aplique inhabilitación por el periodo de un año.
El juez del segundo juzgado penal unipersonal de Puno sentencia: aprobar el acuerdo entre el imputado y el fiscal, sobre la pena y reparación civil vía conclusión anticipada del proceso; condenar a CCCcomo autor del delito Contra la Seguridad Publica, en la modalidad de delito de Peligro Común, en su forma de Conducción de Vehículo Motorizado, en Estado de Ebriedad y; el pago de costas a ser calculada en ejecución de sentencia.

A través de la resolución $\mathrm{N}^{\circ} 14$ del ocho de marzo del dos mil dieciséis, el Segundo Juzgado de Investigación Preparatoria de Puno, resuelve declarar fundado el requerimiento de revocatoria de pena, y se dispone que la pena suspendida se convierta en efectiva (de diez meses con veinte días) girándose las ordenes de captura.

Mediante resolución $\mathrm{N}^{\circ} 15$ del primero de agosto del dos mil dieciséis, se establece que la pena se inicia el treinta de julio de dos mil dieciséis (fecha de la captura), y finaliza el dieciocho de junio del dos mil diecisiete. Y se resuelve, disponer el inicio de la pena, así como el internamiento de YYY.

El veintiocho de noviembre del dos mil dieciséis YYY en su calidad de interno, solicita su liberación condicional. 
Entre los documentos que favorecen su posterior libertad condicional se encuentran:

Un certificado de conducta, emitido por el director del establecimiento penitenciario de Puno, quien certifica que no registra sanción disciplinaria alguna.

Un certificado de computo laboral, expedido por el personal de área de trabajo del establecimiento penitenciario, que certifica que YYY, cumplió con su labor efectiva.

Doscupones de depósito judicial por reparación civil, uno por la suma de doscientos cincuenta nuevos soles y oro por setecientos cuarentaicinco nuevos soles. Un contrato de trabajo, destinado a acreditar la predisposición de YYY, a reinsertarse en la sociedad.

Informe psicológico, el cual contiene:

Datos personales como: edad (36), lugar de nacimiento (Puno), nivel de instrucción (secundaria completa), estadocivil (conviviente), hijos (2), ocupación (construcción civil) y delito (conducir en estado de ebriedad; particularidades físicas, como altura $(1.69 \mathrm{~cm}$.), peso (57 kilos), contextura (delgada), aseo adecuado, postura erguida, vista desviada y desviación de tabique nasal.

Antecedentes significativos: el interno es el segundo de siete hermanos, su padre era maestro de obra y su madre ama de casa, a los nueve años vive violencia familiar, su padre bebía constantemente y golpeaba a su madre, trabajaba desde los ocho años, postula a la universidad para la carrera de arquitectura, pero no logra ingresar, su padre se accidenta en el trabajo rompiéndose la cabeza por lo cual estuvo postrado durante dos meses, por lo cual empieza a trabajar como triciclista, a los diecisiete años empieza a trabajar como peón de construcción, apoyando económicamente en su hogar, y a los diecinueve años conoce a su actual esposa, con la que al dos mil dieciséis llevaba dieciséis años de convivencia.

Características psicológicas del interno al momento de la intervención: en ese momento es calificado como una persona inestable e introvertida, correspondiente al tipo flemático.

En el seguimiento del tratamiento psicológico: el recluso participo,con una frecuencia continua y sin ninguna observación, realizo intervenciones individua-

Revista Derecho - 5 (2019) 103 
les, actividades diversas e intervenciones en familia. En el transcurso de la psicoterapia, se evidencia la voluntad del interno, para trabajar aspectos cognitivos respecto a sus dificultades en el consumo del alcohol

Comportamiento del interno durante su permanencia en el establecimiento penitenciario: el interno se caracteriza por no tener sanciones disciplinarias en el EP, participa voluntariamente en forma continúamostrando disposición al cambio, es sometido a evaluaciones psicológicas en forma constante para observar su progreso en las diferentes áreas de personalidad.

Respecto a los indicadores psicopatológicos, se anota que el interno no muestra indicadores psicopatológicos.

Apreciación psicocriminologica: en este caso se refiere que, el interno tiene autoconciencia del delito, sentimientos de culpa y arrepentimiento. El interno reconoce tratar la falta del control del consumo de bebidas alcohólicas, que es importante reconocer que amistades son positivas que le permitan la reducción de probabilidades de reincidencia.
En cuanto a la probabilidad de reinserción social del interno, se anota que dicha probabilidad es alta.

Un informe social con el siguiente contenido:

Se establecen datos personales como su ocupación en el establecimiento penitenciario (carpintería).

Situación familiar: conviviente cobradora de combi y dos hijos de doce y quince años.

Antecedentes de la vida familiar del interno: se indica que la familia del interno se compone de su esposa, hijos y suegra, con el apoyo incondicional de sus hermanos

Análisis de la estructura y dinámica familiar actual: el interno tubo apoyo de su esposa y todos los integrantes de su familia, quienes asistieron a las visitas constantemente.

Vinculación y acompañamiento del soporte familiar y de redes sociales de apoyo durante el periodo de reclusión: el interno tuvo como soporte familiar a su esposa, madre y hermanos, quienes asistieron constantemente a las 
visitas, desde su ingreso a Establecimiento Penitenciario.

Situación económica: se indica que la situación económica familiar del interno es regular, su esposa trabaja como cobradora de combi, y él se dedica a trabajar dentro del establecimiento penitenciario, en la opción de carpintería, para así poder contribuir con los gastos en su casa.

Tratamiento social: se indica que el interno participo en el tratamiento social durante cuatro meses con dieciocho días, participo de trece sesiones grupales y ocho individuales. Se señala que los resultados alcanzados en el tratamiento social son buenos, mostrando mejoras en el desarrollo parronal y modificando su comportamiento socio-familiar.

Expectativas del interno con relación a su reinserción social: se proveyó que el interno, al salir del E s t a b l e c i m i e $\mathrm{nto}_{\mathrm{t}}$ Penitenciariotrabajaría en la Corporación Jurídica Alerta Legal II, y servicios Técnico de Celulares como personal de Limpieza. Y se calificó como bueno, el entorno social exterior que facilitaría la reinserción social.
Finalmente, se concluyó que el interno reunía las condiciones socio familiares para su reinserción social.

\section{ANALISIS DEL DELITO (CONDUCCION EN ESTADO DE EBRIEDAD)}

\section{El control en los conductores en es- tado de embriaguez}

La criminología muestra dos teorías enfocadas a la conformidad y al refuerzo, la teoría del control social y la teoría de la toma de decisiones. La primera hace referencia a como los grupos controlan el comportamiento de sus miembros, el control de gobiernos con leyes a sus ciudadanos y organizaciones.

Y la segunda, explica los mecanismos intervinientes en la toma de decisiones de los individuos frente a las alternativas que se les presentan.(Klitzner \& Sole-Brito 2. )

Estas dos teorías se han aplicado ante los problemas ocurridos por consumo de alcohol. La criminología ha buscado entender las razones asociadas a la génesis de estas conductas riesgosas, preguntándose por qué se repiten y la razón ante la cual, tanto los medios de prevención como los medios punitivos, funcionan o no en la disminución de la ocurrencia de la conducta desviada en este caso el consumo de alcohol y la

Revista Derecho - 5 (2019) 105 
conducción.(Klitzner \& Sole-Brito, Ross, \& Chambis)

A continuación, se explican brevemente las teorías del control, rational choice y la disuasión social, como bases conceptuales del abordaje criminológico al tema tratado en este artículo.

La teoría clásica del control de(Hirschi, Causes of Delinquency, 1969) transformada después en la teoría del autocontrol (Hirschi \& Gottdredson, Age and the Explanation of Crime, 1983), estudia el individuo y su autocontrol entendido como «la tendencia de evadir actos cuyos costos a largo plazo exceden las ganancias momentáneas». La cual ha sido criticada por no abarcar todos los factores que se ven involucrados en la comisión de un crimen (Felson \& Clarke, 2004)

Se podría argumentar el posicionamiento de esta teoría en el modelo ortodoxo, debido a que la comisión de conductas desviadas ocurre con el propósito de aumentar la utilidad individual, no necesariamente de orden material.(Aloisio \& Trajtenberg, 2009)

De otra forma la teoría de rational choice establece como los actores criminales toman decisiones desde dos propiedades, intencionalidad y racionalidad; la primera se refiere a los objetivos del individuo y sus creencias sobre las consecuencias de las acciones, y la segunda hace referencia a la búsqueda de la maximización de la utilidad esperada, por donde las ganancias exceden los costos. También propone que los individuos no siempre tienen motivaciones económicas, el ofensor es sensible y reactivo a los riesgos de actividad criminal, no actúa completamente desde la racionalidad y la autonomía del agente se ve alterada por su entorno, donde existe una naturaleza emocional, interactiva, transaccional y adaptativa. (Norza, Peñalosa, Duque, Coronado, \& Castro, 2016)

Además, en los resultados del comportamiento existen metas individuales como la excitación, diversión, adrenalina, entre otros. (Cornish \& Clarke, 1986)

Por lo tanto, frente a la disuasión no se debe olvidar el peso ejercido por los factores extralegales, las emociones y las relaciones sociales, donde cometer delitos puede dañar gravemente los vínculos emocionales desarrollados por los individuos con personas cercanas. (Aloisio \& Trajtenberg, 2009)

1.Análisis del Expediente Según las dos Teorías de la Criminología (control social - mecanismos intervinientes)

1.1.- Calificación Legal: Tipificados en el primer párrafo del Artículo $274^{\circ}$ del código Penal que describe: 
«El que encontrándose en estado ebriedad, con presencia de alcohol en la sangre en proporción mayor de 0.5 gramos - litro, o bajo el efecto de drogas tóxicas, estupefacientes, sustancias psicotrópicas o sintéticas, conduce, opera o maniobra vehiculo motorizado, será reprimido con pena privativa de la libertad no menos de seis meses ni mayor de dos años o con prestación de servicios comunitarios de cincuenta y dos a ciento jornadas de inhabilitación, conforme al artículo 36 inciso 7 del Código Penal》.

1. 2. Bien Jurídico Protegido: Es la seguridad del tráfico, sujeto activo quién conduce el vehículo de motor bajo la influencia de los efectos del alcohol, drogas tóxicas, estupefacientes o sustancias psicotrópicas. Sujeto pasivo la colectividad.

1.3. Tipo Objetivo: Sujeto Activo. - El sujeto activo es quien conduce un vehículo motorizado bajo la influencia de los efectos del alcohol, drogas tóxicas, estupefacientes o sustancias psicotrópicas. Sujeto pasivo. - Colectividad. Consumación.- Delito de peligro abstracto, delito de comisión instantánea.

1.4. Tipo Subjetivo: El tipo penal exige necesariamente la presencia del elemento subjetivo dolo para la configuración del injusto penal. Es el conocimiento del autor de hecho de conducir tras haber ingerido las sustancias legalmente relacionadas y de la influencia negativa de las mismas sobre la conducción, como voluntad de actuar en esas condiciones, aceptado por el imputado, se desprende que el acusado ha conducido el vehículo en estado de ebriedad con conocimiento y voluntad, es decir su conducta es dolosa.

1.5.-Antijuricidad: En el presente caso no se advierte la concurrencia de norma permisiva que autorice la realización del acto en principio prohibido por el derecho penal; lo injusto se define como un acto lesivo de bienes jurídicos desaprobados jurídicamente, o «valorados negativamente».

1.6. Culpabilidad: Es el reproche de la conducta típica y antijurídica. En este caso el acusado ha reconocido los hechos imputados por el señor Fiscal y no se ha invocado ninguna causal de exclusión de la culpabilidad por parte de la defensa técnica, no se encuentra uno de los supuestos de exclusión de culpabilidad, por lo tanto, la conducta del acusado, además de ser atípica y antijurídica es culpable, ya que se encontraba en condiciones de entender lo antijurídico de su conducta.

1.7. Autoría: De acuerdo a la teoría del hecho y el artículo 23 del Código Penal, el acusado tiene la condición de autor directo imputado, al respecto no existen cuestionamientos.

\section{2.- Verificación Respecto a la Pena}

2.1. Pena básica que corresponde, de acuerdo con el artículo $274^{\circ}$ primer pá-

Revista Derecho - 5 (2019) 107 
rrafo del código penal, es pena privativa de libertad no menor de seis meses ni mayor de dos años o con prestación de servicios comunitarios de cincuenta $y$ dos a ciento cuatro jornadas e inhabilitación, conforme con el artículo 36 inciso 7).

2.2. En el presente caso, las partes han acordado que al acusado se le imponga la pena de diez meses y veinte días de pena privativa de libertad suspendida, así como inhabilitación para conducir cualquier tipo de vehículo por el periodo de un año.

2.3. Respecto a la suspensión de la pena bajo reglas de conducta se toma en cuenta el artículo $57^{\circ}$ del Código Penal, que señala como requisitos;

«a) que se refiera a pena privativa de libertad no mayor a cuatro años; b) Pronóstico favorable del imputado, que el acusado no volverá a cometer nuevo delito; c) que el agente no tenga la condición de reincidente o habitual, bajo los supuestos del artículo 58 del Código Penal».

3. Verificación de la Legalidad del Acuerdo Respecto de la Reparación Civil.

3.1. De conformidad con los artículos 92 y 93 del Código Penal, y el artículo 393 inciso 3 literal f), la reparación se fija conjuntamente con la pena, y comprende la restitución del bien, o si no es

108 Revista Derecho-5 (2019) posible el pago de su valor; y, la indemnización de daños y perjuicios.

3.2. Las partes han manifestado que se fije la suma se novecientos noventa y cinco nuevos soles, fraccionada en tres cuotas, las mismas que se ha indicado en la parte de acuerdos.

\section{Costas}

De acuerdo con el artículo $497^{\circ}$ del Código Procesal Penal toda decisión que ponga fin al proceso penal o la que resuelva un incidente de ejecución debe establecer quien debe pagar costas del proceso 1) del artículo $500^{\circ}$ del Código Procesal Penal.

5.- Sentencia.- C.C.C Autor del delito Contra la Seguridad Pública, en la modalidad de delitos Contra la Seguridad Pública, en la modalidad de delitos de peligro común, en su forma de conducción de vehículo motorizado, en estado de ebriedad, sentenciado pena diez días y veinte días de privativa de libertad con el carácter de suspendida por el periodo de prueba de año sujeto a las siguientes reglas de conducta: a) Prohibición de frecuentar lugares donde expendan bebidas alcohólicas sin causa justificada; b) Prohibición de ausentarse del lugar de su residencia habitual sin autorización del juez de ejecución penal; c) comparecer en forma personal y obligatoria ante el Juzgado de Ejecución, el último día hábil de cada mes a fin de informar 
de sus actividades y firmar el libro de control respectivo; d) reparar el daño causado, pago de la reparación civil en forma fraccionada. Asimismo, se le impone inhabilitación consistente en la suspensión para conducir cualquier vehículo motorizado por el periodo de un año.

Dispone que el sentenciado deberá pagar las costas; efectos del cumplimento de las reglas de conducta al Juzgado de Investigación, precisando que las cuotas serán pagadas a través de depósito judicial a nombre del juzgado de ejecución.

\section{FACTOR BIOLOGICO BAJO} LA LUZ DE LA CRIMINOLOGIA CLINICA

En el expediente analizado, que trata sobre el delito de conducir en estado de ebriedad, el interno solicita libertad condicional, para tal propósito, se presentan gran variedad de documentos, entre ellos un informe psicológico $y$ un informe social.

A la luz de los factores que aquí son sujetos de análisis, resulta evidente la ausencia de uno de ellos, el cual es el factor biológico, que, a pesar de no ser nueva, su ausencia expone le falta de importancia que recibe.

Respecto a la relación de la criminología con la criminalidad se indica:
"La génesis de los estudios de los factores biológicos como generadores de criminalidad hay que buscarlos en el siglo XVIII, con Franz. Gall, que investigó en los cráneos de reclusos las protuberancias y otras irregularidades para encontrar una explicación biológica a las conductas de estos sujetos)(Arostegui Moreno, 2009)

Poco después de las formulaciones de Gall, el padre de la criminología moderna, Cesare Lombroso, postuló la teoría del «Atavismo moral», que es su propuesta de aplicar el mismo método científico de las ciencias al estudio de la criminalidad, la propuesta que realiza Lombroso no es original suya, ya que anteriormente la había llevado a cabo Augusto Compte, por medio de su obra «Cours de Philosophie Positive», en la que planteaba estudiar el comportamiento humano y la sociedad por medio de la observación, la comparación y la experimentación.

Lombroso ponía de manifiesto la idea del criminal nato y atávico,que era el resultado de un proceso evolutivo incompleto. Lombroso, en sus planteamientos, señalaba que:

«los delincuentes natos y atávicos se caracterizaban por una serie de rasgos físicos, como la frente buidiza y baja, gran desarrollo de los pómulos, orejas en asa, gran pilosidad y braza superior a la estatura. Con tales «descubrimientos", se opone a las formulaciones

Revista Derecho - 5 (2019) 109 
de la Escuela Clásica, lo que provocó un intenso debate científico entre ésta y la Escuela Positiva».(Arostegui Moreno, 2009)

Por su parte, Garofalo citado por Arostegui Moreno consideraba que la Criminología debía de estudiar la delincuencia, tanto desde la vertiente de hecho individual como de fenómeno social, y que el Estado Consideraba además que en el origen de la delincuencia se encontraba una deficiencia psíquica o moral, de carácter hereditario, que provocaba en el sujeto una carencia de sentimientos altruistas y dificultades para vivir en sociedad.

La ciencia biológica trata de localizar en alguna parte del cuerpo humano un factor patológico, disfunción o trastorno orgánico que pueda explicar una conducta delictiva.

Es así que en la actualidad respecto a la incidencia de factores biológicos en la conducta humana se busca explicación a través del estudio de varias disciplinas, entre ellas la neurociencia.

El termino neurociencia hace referencia a las ciencias multidisciplinarias ( $\mathrm{n}$ e u r o a n a t o m í a, neuroquímica,neurofisiología, psicología y neuropsicología)que analizan el sistema nervioso para comprender la base biológica del comportamiento humano.
Un caso emblemático de la neurociencia es el de Phineas P. Gage

«El 13 de septiembre de 1848, Phineas P. Gage se transformó en un instante de un responsable capataz del Ferrocarril Rutland y Burlington en un paria marginado y soez que era incapaz de soportar su vida como marido y como padre. El medio de esta remarcable transformación fue una barra de hierro de 3 centímetros de grueso y 109 centímetros de largo que atravesó el cerebro de Gage tras un grotesco accidente con pólvora negra. La explosión le dejó aturdido, pero no le mató. De forma llamativa, Gage vivió 12 años más tras su transformación, pero el accidente pareció privarle de todo sentido moral. Se convirtió en un vagabundo, asumiendo trabajos temporales en granjas y atracciones de feria.» (Glass, 2006)

Lo esencialmente interesante en este caso es como se produjeron y explicaron los cambios de comportamiento (de uno amable a otro agresivo, teniendo prácticamente a una persona completamente diferente de la que fue Phineas) a partir de un traumatismo en una determinada zona del cerebro. El hecho de que alguien pasara de ser una persona muy amable a otra completamente grosera y malhumorada, contribuyo a fundamentar la idea de la existencia de correlación entre el lóbulo frontal y la ética.

110 Revista Derecho - 5 (2019) 
«Pero no fue hasta el uso de la neuroimagen que se hizo posible una localización más certera de las zonas cerebrales que pudieron correlacionarse con cuestiones de personalidad. En concreto, parece ser que el deterioro (por lesión o desequilibrio) de una específica zona de la corteza prefrontal hace que se pierda capacidad para planificar el futuro, para seguir las reglas sociales que previamente se han usado, y para decidir sobre cursos de acción ventajosos para la supervivencia. La relevancia de la cuestión radica en la afectación del mecanismo de recompensa a corto, medio y largo plazo, que interviene en las adicciones, conductas compulsivas, pero también en la forma habitual de enfrentarnos a las expectativas. Los actuales estudios de la química cerebral en áreas subcorticales profundas permiten ver, en tiempo real, cuáles son los cambios en la oxigenación y otras modificaciones, lo que ha llevado a concluir que con cierta distribución de sustancias químicas en nuestro cerebro, cambiar de conducta cuando una recompensa largamente esperada no se verifica es muy complejo o también que la intensa actividad en determinadas zonas cerebrales en casos de enamoramiento y amor materno, hacen que se pierda la posibilidad de utilizar otros recursos y otras conexiones, con consecuencias para la vida social. Por ejemplo, se ha defendido que las ganas de pelearse con los jefes disminuyen conforme el amor materno y el romántico se sedimentan y se viven como satisfactorios»(Narvaez, 2012)

Como se evidencia en el párrafo anterior, Maribel Narváez indica que gracias a la tecnología de la neurociencia se ha podido llegar a lo que actualmente se conoce como neurolaw o neoroderecho, y que desde 1991 ya se hablaba de neurolaw como un ámbito de intersección entre neurociencia y derecho.

\section{METODOS DE LA CRIMINOLOGIA CLINICA EN LA DETERMINACION DE LA LIBERTAD CONDICIONAL}

El objeto a estudiar de la criminología clínica es el hombre. Quiroz Guaron citado por Rodríguez Manzanera (1981)indica que, así como es el enfermo el que proporciona el material para el médico, el delincuente es el que da nacimiento a la Antropología Criminológica, a la Psicología, Biología y Sociología Criminológicas, y a un reciente cambio de actitud de la sociedad frente al delincuente al que primero eliminó (muerte, esclavitud, segregación), luego simplemente lo conservo, y en nuestros días se esfuerza por tratarlo, técnicamente para esconderlo y reinsertarlo en la sociedad.

Una de las preocupaciones más importantes entre los criminólogos clínicos es, el respeto a los derechos y la

Revista Derecho - 5 (2019) 111 
dignidad del hombre, delincuente o no, así nos lo hace ver la frase:

«Antes de llegar a violar la ley, el delincuente es un individuo que lucha por la existencia». (Tullio, 1955)

Sabemos que la única forma de lograr un futuro mejor para la humanidad, es el anteponer a todo problema político o social aquel de la mejoría de la persona humana.

El criminólogo clínico manejará una serie de métodos fundamentales y complementarios. Los métodos fundamentales son:

\subsection{La entrevista criminológica, con el conocimiento personal y directo del individuo.}

En el expediente fue presentado un informe social, donde se establecieron datos personales del interno, como su ocupación en el establecimiento penitenciario el cual fue carpintería; La situación familiar del interno donde se señaló que su conviviente trabajaba como cobradora de combi y además tiene dos hijos de doce y quince años, quienes aún para ese entonces estudiaban.

Se indica que la familia del interno se compone de su esposa, hijos y suegra, con el apoyo incondicional de sus hermanos, se manifestó que el interno tuvo apoyo de su esposa y todos los in- tegrantes de su familia, quienes asistieron a las visitas constantemente.

Es evidente que durante su estadía en el establecimiento penitenciario el interno tubo como soporte familiar a su esposa, madre y hermanos, quienes asistieron constantemente a las visitas, desde su ingreso a Establecimiento Penitenciario.

Respecto a su situación económica, se indicó que la situación económica familiar del interno era regular, su esposa trabajaba como cobradora de combi, mientras queél se dedicó a trabajar dentro del establecimiento penitenciario, en la opción de carpintería, para así poder contribuir con los gastos en su casa.

En el informe social se anota que, dentro del establecimiento penitenciario, el interno participo en el tratamiento social durante cuatro meses con dieciocho días, participo de trece sesiones grupales y ocho individuales. Se señala que los resultados alcanzados en el tratamiento social son buenos, mostrando mejoras en el desarrollo parronal y modificando su comportamiento.

\subsection{Examen médico, con ausculta- ción e historia médica.}

En el expediente analizado no se muestra historia médica del interno, a excepción de la mención de que el ojo

112 Revista Derecho - 5 (2019) 
del lado izquierdo de la cara del interno, tiene la vista desviada (estrabismo).

\subsection{Examen psicológico, dando como resultado datos sobre la personalidad.}

Examinado que mediante las pruebas psicológicas se observan que es una persona con una tipológica altamente inestable e introvertido, de temperamento correspondiente al tipo flemático.

En cuanto a sus funciones psíquicas básicas al inicio de su re reclusión eran normales respecto a la atención, conciencia, orientación, precepción, memoria. En cuanto a las funciones psíquicas superiores se observaba pensamiento coherente, leguaje normal e inteligencia normal promedio.

\section{Apreciación psicocriminológica}

Interno de 36 años de edad, de raza mestiza, contextura delgada, de presencia arreglada y aseo adecuado, aparenta la edad cronológica mencionada, de condición socioeconómica regular, refiere el interno. De acuerdo a los resultados de las evaluaciones en intervención psicológica en el tiempo de su reclusión se observan autoconciencia del delito, sentimientos de culpa y arrepentimiento considerándose responsable respecto al hecho por el que lo sindican. La psicoterapia se enfoca en esta- blecer aspectos y condiciones personales importante para lograr el cambio del interno, por ello de manera considerable se puede referir que el interno reconoció tratar la falta del control del consumo de bebidas alcohólicas, que es importante reconocer que amistades son positivas para su crecimiento personal, desarrollar y fortalecer competencias sociales que le permiten una reducción de probabilidad de reincidencia delictiva. Hoy en día ha desarrollado más independencia y estabilidad emocional. Por otro lado, considera que a través del trabajo se obtienen logros personales.

\subsection{Encuesta social, sobre el me- dio en que el individuo se ha de- sarrollado.}

Antecedentes de la vida familiar del interno

La familia del interno, que está compuesta por su esposa, dos hijos y su suegra, el interno es el segundo de siete hermanos, proviene de una familia organizada, cuenta con el apoyo de sus hermanos los que siempre estuvieron en todo momento.

Análisis de la estructura y dinámica familiar actual

El interno a la fecha cuenta con el apoyo de su esposa y de todos los integrantes de su familia, los que siempre

Revista Derecho - 5 (2019) 113 
estuvieron al pendiente de él, y asisten a sus visitas constantemente, los que se encuentran preocupados por el proceso el cual se encuentra recluido en el recinto penitenciario de Puno.

Vinculación y acompañamiento familiar y de redes sociales de apoyo durante el periodo de reclusión

$\mathrm{El}$ interno tiene como soporte familiar a su esposa, madre y hermanos, los que asisten a las vistas en forma constante desde que ingreso al establecimiento penitenciario.

\section{- $\quad$ Situación de vivienda}

Su vivienda contaba con los servicios básicos completos.

Situación económica (interno y familia)

La situación económica actual de la familia y esposa es regular, ya que la esposa trabaja como cobradora de combi en el servicio urbano, así mismo el interno trabaja en el establecimiento penitenciario en la opción de carpintería; para así poder ayudar a su esposa e hijos con los gastos de la casa.

- Tratamiento social

Participo en el tratamiento social, con una frecuencia regular

114 Revista Derecho-5 (2019)
Tiempo que participo en tratamiento social: cuatro meses, con dieciocho días Numero de sesiones de tratamiento: grupal: trece individual: ocho

Las formas en las que intervino son los talleres multidisciplinarios, tratamiento individual, participación de la familia, tratamiento grupal, actividades diversas.

El resultado alcanzado en el tratamiento es bueno, mejoro su desarrollo personal, modifico positivamente se comportamiento socio-familiar y compromiso familiar alcanzado en el proceso de resocialización.

El interno a la fecha no registra sanciones disciplinarias, en el establecimiento penitenciario, de acuerdo al libro de registro de conductas.

- Expectativas del interno con relación a su reinserción social

Laborales: el interno al egresar del establecimiento penitenciario se dedicará a trabajar en la Corporación Jurídica Alerta Legal II y servicios técnicos de celulares como personal de limpieza.

\section{INFLUENCIA DE LA CRIMINOLOGIA CLINICA EN EL INFORME SOCIAL}

$\mathrm{La}$ influencia que recibe el informe social de la criminología clínica, pue- 
de ser evidenciado atreves del uso dediversos métodos de la criminología clínica, los que son:

La entrevista criminológica: en este método se atiende, el conocimiento directo y personal del interno

Encuesta social: referente al medio en el que el interno se desarrolló.

La observación directa; que tiene como finalidad determinar, la actitud íntima del sujeto, y su comportamiento actual.

\section{CONCLUSIÓN:}

La criminología clínica es una corriente criminológica y, nació como tal con César Lombroso. El concepto ha sido desarrollado por múltiples autores como Benigno Di Tullio, Ferri, Laurent y Pinatel entre otros. En base a su definición, la criminología clínica intenta explicar el delito a partir del estudio del delincuente. Estudio que se basa en el diagnóstico, pronóstico y tratamiento de dicho sujeto. Por tanto, una parte muy importante de la misma es la investigación de nuevas teorías y métodos. Métodos como el estudio del caso, la comparación de delincuentes y no delincuentes, el análisis estadístico, la aproximación tipológica y los estudios longitudinales.
La criminología la ciencia de las conductas antisociales y criminales, basada en la observación y el análisis profundo de casos individuales, sean éstos normales, anormales o patológicos.

La Criminología Clínica es ante todo Criminología aplicada. Existen tres niveles de interpretación: el conductual (crimen), el individual (criminal), y el general (criminalidad); la Criminología clínica opera en el segundo nivel, analiza al sujeto antisocial en concreto, en su realidad personal e irrepetible.

La corriente de la criminología clínica considera al hombre como una unidad bio-psicosocial, es una totalidad, ente bio-psicosocial, porque está formado por de un potencial biológico, tiene una herencia, tiene una psique, que es su forma de ser, más aún es un ser que vive en sociedad, por lo tanto, su pensamiento y su forma de ser es influenciada por la sociedad, llevándonos a analizar las causas biológicas, psicológica y sociológicas.

La criminología clínica entendida como la conjugación de un todo, de aspectos bilógicos psicológicos y sociales, llega a entender cuestiones como la comisión de un delito, no solo desde le delito mismo, si no desde un punto de vista más humano, donde para resolver cuestiones de dicha índole se requieren de estudios, como ya se mencionó anteriormente con contendido

Revista Derecho - 5 (2019) 115 
biopsicosocial, donde el expediente analizado se toma en cuenta un informe psicológico, a través del cual se trata de demostrar el desarrollo emocional y efectiva del reo, llegando a concluir que queda apto para su reinserción social. Además se toma en cuenta el aspecto sociológico donde en el expediente hace mención al informe social del cual se toman aspectos de la vida del reo para poder entender el entorno que lo lleva a la omisión del delito, también se estudian aspectos, que influencian en la vida del reo durante la estadía en el establecimiento penitenciario, aspectos como la importancia del apoyo familiar y proyección futura del reo en la sociedad, ultimo él es aspecto bilógico el cual no es tomado en cuenta en el expediente estudiado, sin embargo cabe resaltar la importancia de este.

\section{Referencias}

Aloisio, C., \& Trajtenberg, N. (2009). La racionalidad en las Teorias C r i m i n o log i c a s Contemporaneas. Uruguay desde la sociologia, 279-294.

Arostegui Moreno, J. (Marzo de 2009). La Biologia Humana y la Conducta Criminal. Revista de Criminologia y Ciencias Forenses, 4, 35 - 42. Obtenido de C:/Users/docente/ Downloads / DialnetLaBiologia HumanaYLa
Conducta Criminal2869876.pdf

Cornish, D., \& Clarke, R. (1986). The Reasoning Criminal: Rational Choice Perspectives on Offending. Hague: SpringerVerlag.

Felson, M., \& Clarke, R. (2004). Routine Activity and Rational Choice. Transaction Publishers.

Glass, J. (2006). The Passion of Phineas Gage \& Selected Poems. Ahadada.

Hirschi, T. (1969). Causes of Delinquency. Bekerley: University of California Press.

Hirschi, T., \& Gottdredson, M. (1983). Age and the Explanation of Crime. American Journalist Sociology.

Klitzner \& Sole-Brito, 2. (s.f.).

Klitzner \& Sole-Brito, 2., Ross, 1., \& Chambis, 1. (s.f.).

Narvaez, M. (2012). El Impacto de la Neurociencia Sobre el Derecho: el Caso de la Responsabilidad Subjetiva. Revista Telemática de Filosofía del Derecho, 195-230.

116 Revista Derecho-5 (2019) 
Norza, E., Peñalosa, P., Duque, B., Co- $\quad$ Rodriguez Manzanera, L. (1981). ronado, J., \& Castro, D. Criminología. México: Porrúa. (2016). Percepcion de Impunidad: Precipitante del Tullio, B. (1955). Delitto e Personalita. ItaCrimen en Bogotá. Revista lia: Guiffré Editore.

de Derecho, 39-70. 
118 Revista Derecho - 5 (2019) 